\title{
The latest generation drive for electric buses powered by SiC technology for high energy efficiency
}

\author{
Janusz Biliński ${ }^{1, *}$ \\ ${ }^{1}$ MEDCOM Sp. z o.o., ul. Jutrzenki 78A, 02-230, Warsaw, Poland
}

\begin{abstract}
High energy efficiency and increasing the working frequency of the converter will make it possible to minimize the size of the cooling system and reduce energy consumption. The use of the SiC technology in propulsion drives increases the efficiency of the converter by $1 \div 1.5 \%$. Simultaneously, higher working frequency reduces losses in the traction motor, significantly lowering the cost of the energy consumed by the vehicle. Auxiliary converters using the SiC technology are a new quality. The reduction of weight and size is very significant (ca. $40 \div 50 \%$ ). Higher switching frequency reduces the size of magnetic components (ca. 80\%), and higher converter efficiency minimizes the size of the cooling system. The overall efficiency of the converter is extremely high $(94 \div 96 \%)$. This paper presents comparison of $\mathrm{Si}$ and $\mathrm{SiC}$ parameters which are important for modern EV solutions. Paper presents also parameters of $\mathrm{SiC}$ traction inverter and auxiliary converter, designed and manufactured as state-of-the-art product for modern electric bus.
\end{abstract}

\section{Technology of silicon carbide components ( $\mathrm{SiC})$}

Modern electric buses, which are operated in cities around the world, use traction inverters and static converters to power on board equipment of the e-bus. In the case of modern e-buses, they provide higher power than traditional rotating inverters. This device, commonly used in electrical traction units, is currently designed and manufactured using IGBT (Insulated Gate Bipolar Transistor) transistor technology. By achieving high reliability and electrical efficiency, technology widely used since the mid-1990s is now recognised as a market standard and used by most manufacturers of electronic components [1-13].

According to the predictions of research institutes, vehicle manufacturers and component manufacturers, in the near future IGBT technology will be replaced by SiC technology [14-16].

Power elements based on the new $\mathrm{SiC}$ technology are built on silicon carbide semiconductors (Silicon Carbide, $\mathrm{SiC}$ ), while the current technology is based on silicon semiconductors. Intensive R \& D work carried out by component manufacturers has enabled the availability of $\mathrm{SiC}$ components with a reliability similar to that of conventional components and has led to a gradual reduction in production costs, which now allow these components to be commercially used in power electronics.

In traction applications where low weight, small size and high efficiency are the most important parameters of power electronics, the new silicon carbide (SiC) semiconductor technology is changing the game rules. The new semiconductor material has significantly better physical properties than silicon $(\mathrm{Si})$, which allows to build on its base the best power instruments: diodes and transistors. It can be noted that compared to commonly used silicon elements, $\mathrm{SiC}$ power elements:

- have shorter switching times,

- have lower voltage drops during conductivity,

- can operate at higher joint temperatures.

As a result, power losses in transformer systems designed with the new technology are significantly lower, which allows to reduce energy consumption, but also to reduce the weight and size of cooling systems. You can also increase the switching frequency of semiconductor components and reduce the weight and size of passive components [17-19].

Application of the new $\mathrm{SiC}$ technology in drive inverters allows to increase their energy efficiency by $1 \div 1.5 \%$. At the same time, the higher switching frequency reduces power losses in the propulsion engine, reducing the power consumed by the vehicle [20,21].

Static converters using silicon carbide components are a new quality - dimensions and weight can be reduced by up to $50 \%$. The higher switching frequency allows to minimize the size of magnetic elements up to $80 \%$, while lower losses reduce the dimensions of cooling systems. The overall energy efficiency of the inverters is very high, ranging from $94 \div 96 \%$.

\footnotetext{
* Corresponding author: janusz.bilinski@medcom.com.pl
} 
Three types of semiconductor components are now available for traction applications using the new silicon carbide technology (Fig. 1):

- Silicon carbide Schottky diodes

- Hybrid modules (silicon IGBTs with $\mathrm{SiC}$ Schottky diodes)

- "Full-SiC" modules ( $\mathrm{SiC}$ MOSFET + $\mathrm{SiC}$ diodes).

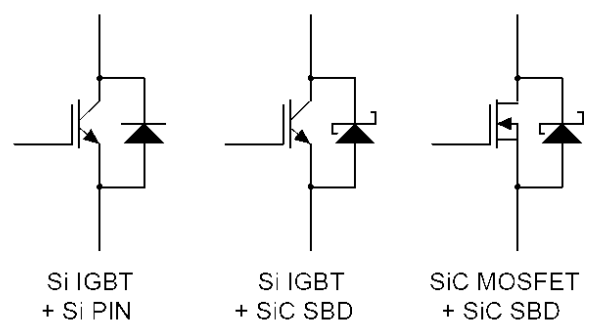

Fig. 1. SiC semiconductor component types - IGBT, hybrid IGBT (transistor with $\mathrm{SiC}$ diode), full $\mathrm{SiC}$ ( $\mathrm{SiC}$ MOSFET with $\mathrm{SiC}$ diode).

In Fig. 2, a comparison of parameters of IGBT Si and $\mathrm{SiC}$ elements for electrical traction power equipment applications is presented.
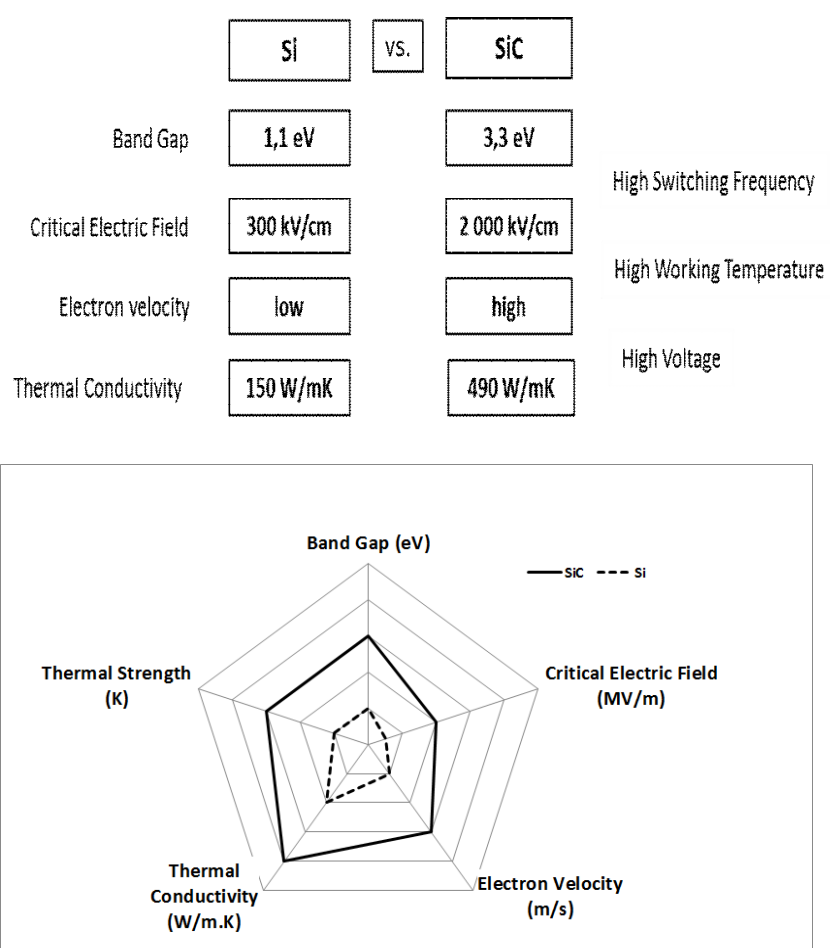

Fig. 2. Comparison of basic parameters of IGBT Si and $\mathrm{SiC}$ elements.

Utilizing the advantages of the latest generation $\mathrm{SiC}$ components also requires a new approach to device design, as shown in Fig. 3.

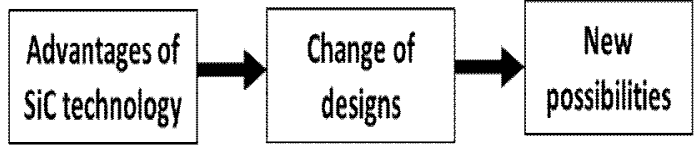

Higher operating temperatures Smaller heatsinks Reduction of size

Lower switching loss Smaller magnetic components Reduction of weight

Higher switching frequency Smaller cooding system High efficiency and power density

Fig. 3. A new approach to the design of SiCs.

\section{Traction inverter integrated with the auxiliary converter with SiC power elements}

The FT-160-600 traction inverter is designed for driving electric buses. The inverter is made in full-SiC technology. The drive inverter is controlled by a DSP (Digital Signal Processor) controller using the FOC SVPWM (Field Oriented Control Space Vector Pulse Width Modulation) algorithm. The controller guarantees optimum control of the asynchronous motor and ensures very good traction and high level of driving comfort. The design of the traction inverter allows it to be used for supplying the "classic" traction motor as well as motors integrated with the bus drive axis. The block diagram of the e-bus traction system with SIC inverter and converter is shown in Fig. 4.

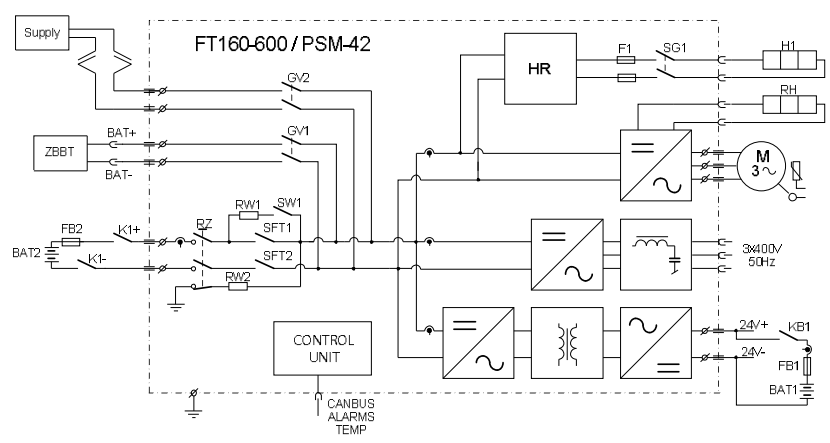

Fig. 4. Block diagram of traction system with inverter and converter FT-160-600 / PSM-42 SiC.

The inverter is equipped with natural air cooling. The system meets all European standards and the requirements of Regulation No. 100 (R100) on safety and radio interference. The system is installed on the roof of the vehicle. It is equipped with an integrated high voltage switchgear connecting the traction battery, buffer power supplies and precharging system in one box. The latest generation of applied elements and advanced diagnostic system guarantee a high level of reliability and low operating costs. The PSM-42 static converter with a power of $30 \mathrm{kVA} / 3 \times 400 \mathrm{~V}$ AC and $12 \mathrm{~kW} / 24 \mathrm{~V}$ DC is placed in the same box. Fig. 5 shows the device view. The technical parameters of the $\mathrm{SiC}$ inverter and $\mathrm{SiC}$ converter are shown in Table 1. 

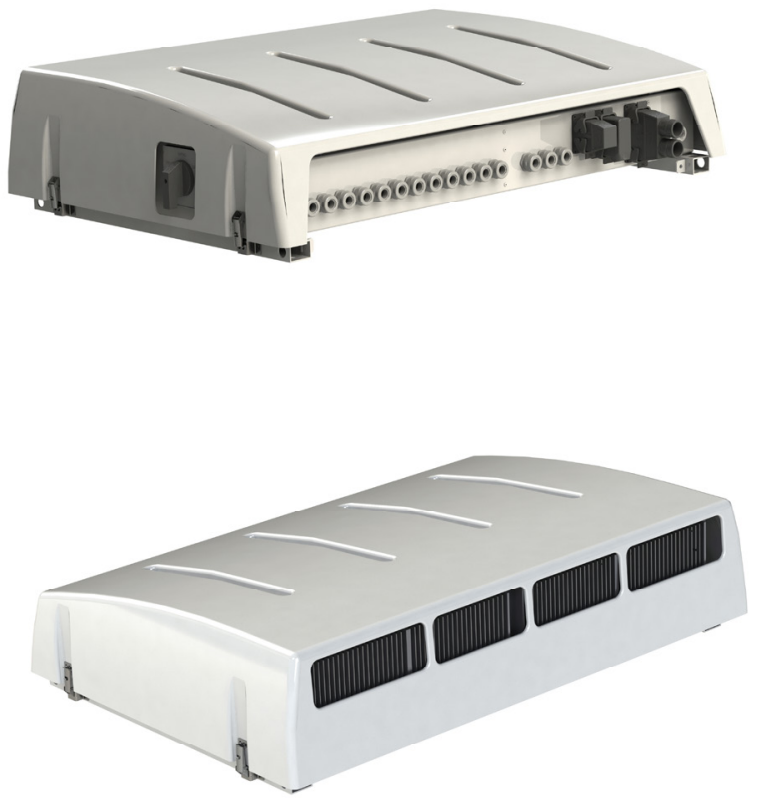

Fig. 5. View of the FT-160-600 inverter.

Table 1. Parameters of the FT-160-600 SIC inverter and the PSM-42 SiC converter.

\begin{tabular}{|l|l|}
\hline \multicolumn{2}{|l|}{ Specification of FT-160-600 inverter } \\
\hline Input voltage & $520-750 \mathrm{VDC}$ \\
\hline Auxiliary voltage & $\begin{array}{l}24 \mathrm{VDC} \\
+30 \% \ldots-40 \%\end{array}$ \\
\hline Rated current & $300 \mathrm{Arms}$ \\
\hline Maximum current & $500 \mathrm{Arms}$ \\
\hline Rated power & $160 \mathrm{~kW}$ \\
\hline Frequency & $0 \div 350 \mathrm{~Hz}$ \\
\hline PWM frequency & $2-6 \mathrm{kHz}$ \\
\hline Insulation strength & $2,5 \mathrm{kV}$ \\
\hline Cooling & natural, air \\
\hline Dimensions & $1430 \times 990 \times 330 \mathrm{~mm}$ \\
\hline
\end{tabular}

\begin{tabular}{|l|l|}
\hline \multicolumn{2}{|l|}{ Specification of the PSM-42 converter } \\
\hline Input voltage & $520-750 \mathrm{VDC}$ \\
\hline Auxiliary voltage & $24 \mathrm{VDC}+30 \%-40 \%$ \\
\hline AC output nominal power & $30 \mathrm{kVA}$ \\
\hline AC output voltage & $3 \times 400 \mathrm{VAC}+/-10 \%$ (sinus) \\
\hline AC output frequency & $50 \mathrm{~Hz}$ \\
\hline AC output current & $43 \mathrm{~A}$ \\
\hline Overcurrent & $1.5 \mathrm{In} / 30 \mathrm{sec}$. \\
\hline Electronic protection & $\begin{array}{l}\text { overcurrent } / \text { overvoltage/ } \\
\text { overheating }\end{array}$ \\
\hline DC output nominal power & $12 \mathrm{~kW}$ \\
\hline DC output voltage & $24 \mathrm{VDC}$ \\
\hline DC output current & $500 \mathrm{~A}$ \\
\hline Insulation strength & $2,5 \mathrm{kV}$ \\
\hline Cooling & natural, air \\
\hline Weight of the set & $165 \mathrm{~kg}$ \\
\hline
\end{tabular}

\section{Summary}

Electric vehicles are an important part of life around the world, and this is why it is important to save energy. Power elements based on $\mathrm{SiC}$ technology allow for significant reduction of energy losses, increasing the efficiency of the inverters. The expected reduction of dynamic losses is approx. 50\% compared to IGBT technology. In addition, power elements based on $\mathrm{SiC}$ technology have a significantly higher operating speed, which allows higher frequencies to be used, allowing the use of smaller and lighter magnetic components, which can reduce the weight and size of devices by more than $40 \%$ compared to traditional designs. Increased switching frequency reduces traction engine losses by lowering the energy cost of the vehicle.

Improvements in efficiency combined with a decrease in the weight and size of equipment is now one of the key improvements sought by electric vehicle manufacturers. Components based on $\mathrm{SiC}$ technology reduce the weight of the whole vehicle, reducing energy consumption. The overall efficiency of $\mathrm{SiC}$ converter is ca. $94 \div 96 \%, \mathrm{SiC}$ technology of inverter gives $1 \div 1.5 \%$ better value compared to IGBT.

An additional advantage, which is particularly important for vehicle passengers, is the reduction of noise generated by devices based on $\mathrm{SiC}$ components, allowing for greater comfort of travel.

The use of semiconductor components in $\mathrm{SiC}$ technology in the propulsion system and power supply will reduce energy consumption by about $5 \div 15 \%$ compared to traditional silicon technology. The use of $\mathrm{SiC}$ technology is a true technological revolution in the design of innovative power electronic devices for public transport.

\section{References}

1. P. Baginski, Power Modules for Charger Applications (2016). Viewed 20 September 2017 https://www.vincotech.com/support-anddocuments/technical-library.html

2. D. Aggeler, Bidirectional Galvanically Isolated 25 kW $50 \mathrm{kHz} 5 \mathrm{kV} / 700 \mathrm{~V} \mathrm{Si-SiC} \mathrm{Super} \mathrm{Cascode/Si-}$ IGBT DC-DC Converter (PhD thesis, ETH Zurich, Switzerland, 2010)

3. M. Frisch, Advantages of SiC Schottky Diodes in Fast Switching Power Electronics Solutions (2010). Viewed 20 September 2017 https://www.vincotech.com/support-anddocuments/technical-library.html

4. M. Frisch, and E. Temesi, Topologies Benefits of NPC Inverter (2010). Viewed 20 September 2017 https://www.vincotech.com/support-anddocuments/technical-library.html

5. J. Liu, K.L. Wong, A. Scott, and J. Mokken, Performance Evaluations of Hard-Switching Interleaved DC/DC Boost Converter with New 
Generation Silicon Carbide MOSFETS (2016). Viewed 20 September 2017

https://www.mouser.jp/pdfDocs/Cree-

Power Article 4.pdf

6. Mitsubishi Electric, Mitsubishi Electric to Begin Shipment of Silicon Carbide Power Module Samples (2012). Viewed 20 September 2017 http://www.mitsubishielectric.com/news/2012/0709. $\underline{\mathrm{html}}$

7. Mitsubishi Electric, Mitsubishi Electric Delivers World's First SiC Auxiliary Power Supply Systems for Railcars (2013). Viewed 20 September 2017 http://www.mitsubishielectric.com/news/2013/0326a.html

8. K. Mrinal, et al., $10 \mathrm{kV}, 120 \mathrm{~A} \mathrm{SiC}$ Half H-Bridge Power MOSFET Modules Suitable for High Frequency, Medium Voltage Applications, 2011 IEEE Energy Conversion Congress and Exposition, Phoenix, AZ, USA, 4, 2689-2692 (2011)

9. P.G. Neudeck, Silicon Carbide Technology. The VLSI Handbook (NASA Glenn Research Center, CRC Press LLC 2006)

10. R. Singh, Silicon Carbide Thyristors usher in the Smart Grid Revolution (2012). Viewed 20 Sept. 2017 https://www.genesicsemi.com/images/references/tra de journals/bodo 02-12.pdf

11. R. Singh, et al., 1200 V-class 4H-SiC "Super" Junction Transistors with Current Gains of 88 and Ultra-fast Switching capability, Materials Science Forum, 717-720, 1127-1130 (2012)

12. S.G. Sundaresan, et al., $12.9 \mathrm{kV} \mathrm{SiC} \mathrm{PiN} \mathrm{diodes}$ with low on-state drops and high carrier lifetimes, Materials Science Forum, 717-720, 949-952 (2012)

13. S.G.Sundaresan, et al., Integrated $\mathrm{SiC}$ Anode Switched Thyristor Modules for Smart-Grid Applications, Materials Science Forum, 717-720, 1159-1162 (2012)
14. S. Taranowich, Si vs. GaN vs. SiC: Which process and supplier are best for my power design? (EDN Network, Power Management Design Center, 2013). Viewed 20 Sept. 2017

https://www.edn.com/design/powermanagement/4409627/Si-vs--GaN-vs--SiC--Whichprocess-and-supplier-are-best-for-my-power-design

15. How2Power Today, Dual SiC MOSFET Modules Promise High Efficiency (2009). Viewed 20 Sept. 2017 https://www.how2power.com/newsletters/0911/prod ucts/PowerexSiC.pdf

16. Yole Development, Power SiC 2017: Materials, Devices, Modules, And Applications report (2017). Viewed 20 Sept. 2017 http://www.yole.fr/STATUS SIC MARKET TEC HNOLOGY TRENDS.aspx

17. ROHM Semiconductor, SiC Power DeviceTechnology (2013). Viewed 20 Sept. 2017 https:/www.rohm.com/documents/11308/2420552/ SiC power device-catalog.pdf

18. ROHM Semiconductor, SiC Power Devices and Modules. Application Note (2014). Vieved 20 Sept. 2017 https://d1d2qsbl8m0m72.cloudfront.net/en/products/da tabook/applinote/discrete/sic/common/sic appli-e.pdf

19. ROHM Semiconductor, 2016. Silicon Carbide Schottky Barrier Diodes. White Paper, vieved 20 Sept. 2017

https://www.rohm.com/documents/11308/12928/RO HM SiC+Diodes wp.pdf

20. E. Hagesawa, et al., Hybrid SiC Power Module With Low Power Loss, Power Electronics Europe, 6, 2023 (2012)

21. Circuits Today, JFET and MOSFET Comparison (2017). Viewed 20 Sept. 2017

http://www.circuitstoday.com/ifet-and-mosfetcomparison 